OPEN ACCESS

\section{Micro-XRF for characterization of Moroccan glazed ceramics and Portuguese tiles}

To cite this article: A Guilherme et al 2013 JINST 8 C02055

View the article online for updates and enhancements.

\section{Related content}

\author{
- Investigation of charge collection in a \\ CdTe-Timepix detector \\ D Krapohl, C Fröjdh, E Fröjdh et al. \\ X-ray fluorescence imaging system for fast \\ mapping of pigment distributions in cultural \\ heritage paintings \\ A Zieliska, W Dbrowski, T Fiutowski et al. \\ - Particle detectors based on InP Schottky \\ diodes \\ R Yatskiv and J Grym
}

\section{Recent citations}
- A combined XRF/Monte Carlo simulation study of multilayered Peruvian metal artifacts from the tomb of the Priestess of Chornancap Antonio Brunetti et al
The ceramics of Malpaís of Zacapu. Michoacán, Mexico, during the Early and Middle Postclassic periods (900-1450AD). Micro-chemical characterization of surface paintings
E. Jadot et al
- A new Monte Carlo code for simulation of the effect of irregular surfaces on X-ray spectra
Antonio Brunetti and Bruno Golosio

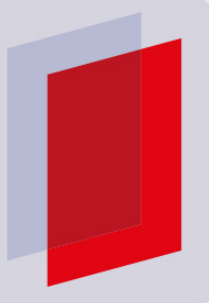

\section{IOP ebooks}

Bringing you innovative digital publishing with leading voices to create your essential collection of books in STEM research. Start exploring the collection - download the first chapter of every title for free. 


\title{
Micro-XRF for characterization of Moroccan glazed ceramics and Portuguese tiles
}

\author{
A. Guilherme, ${ }^{a}$ M. Manso, ${ }^{a}$ S. Pessanha, ${ }^{a}$ A. Zegzouti, ${ }^{b}$ M. Elaatmani,${ }^{b}$ \\ R. Bendaoud, ${ }^{b}$ J. Coroado, ${ }^{c}$ J.M.F. dos Santos ${ }^{d}$ and M.L. Carvalho ${ }^{a, 1}$ \\ ${ }^{a}$ Atomic Physics Centre, University of Lisbon, \\ 1649-003 Lisbon, Portugal \\ ${ }^{b}$ Faculté des Sciences Semlalia, Université Cadi Ayyad Marrakech, \\ BP 2390, Marrakech, Morocco \\ ${ }^{c}$ Dept. Arts, Conservation \& Restoration, Polytechnic Institute of Tomar, \\ Tomar, Portugal \\ ${ }^{d}$ GIAN, Physics Department, University of Coimbra, \\ 3004-516 Coimbra, Portugal \\ E-mail: luisa@cii.fc.ul.pt
}

ABSTRACT: A set of enamelled terracotta samples (Zellij) collected from five different monuments in Morocco were object of study. With the aim of characterizing these typically Moroccan artistic objects, X-ray spectroscopic techniques were used as analytical tool to provide elemental and compound information. A lack of information about these types of artistic ceramics is found by the research through international scientific journals, so this investigation is an opportunity to fulfill this gap.

For this purpose, micro-Energy Dispersive X-ray Fluorescence ( $\mu$-EDXRF), and wavelength dispersive X-ray Fluorescence (WDXRF) and X-ray Diffraction (XRD) were the chosen methods. As complementary information, a comparison with other sort of artistic pottery objects is given, more precisely with Portuguese glazed wall tiles (Azulejos), based in the Islamic pottery traditions. Differences between these two types of decorative pottery were found and presented in this manuscript.

KEYWORDS: X-ray detectors; X-ray fluorescence (XRF) systems; Interaction of radiation with matter; Ionization and excitation processes

\footnotetext{
${ }^{1}$ Corresponding author.
} 


\section{Contents}

1 Introduction 1

2 Experimental methodology 2

2.1 Micro Energy Dispersive X-ray Fluorescence (EDXRF) 2

2.2 Wavelength Dispersive X-ray Fluorescence (WDXRF) 3

3 Results and discussion $\quad 3$

3.1 The ceramic body 3

3.2 The colors 5

3.3 The white/glaze 5

4 Conclusions $\quad 7$

\section{Introduction}

Islamic traditions are well known by their ability to produce wonderful artistic glazed colored ceramics. This art has been introduced in Iberian Peninsula by the Muslims, since their occupation until the 15th century, and some similarities between the production processes is expected.

Documental proofs show that there are many types of artistic pottery objects. Variables such as raw materials, recipes used by the potter (mixing techniques, proportions, etc.), firing stages, surface treatments (slips, glazes, etc.) and decorative motifs dictate the final product and, hence, the class or type of object [1]. The investigated samples are enameled tiles used for decoration (Zellij) from five important monuments in Marrakech (Morocco) from XVI-XX centuries and ceramics and tiles from two Portuguese production centers from XVII century.

So far, the references regarding this type of Moroccan artistic objects are very limited and there is no compositional study available. The work by Zarghili et al. [2] describes a method that allows Arabo-Moresque décor image retrieval, especially for the case of Zellij's decors, which cover great surfaces; the spine is formed by many connected polygonal forms. The other study found was the one from Casas et al. [3], in which the authors present archaeometric dating techniques giving a new contribution to the databases from samples from a region (Morocco) and a time (16th century). However, no chemical characterization has been made on these pieces so far and therefore this paper aims to fulfil this gap.

The type of samples in the following is Zellij, a kind of art which is typically Moroccan. They are characterized by a terracotta body with an enameled surface and they belong to the production period between XVII and XIX centuries. This sort of objects is prepared manually. Further insight about the manufacturing procedures involved can be found in [4]. A more detailed explanation about the site from where these samples were retrieved can be found in the following references [5]-[12]. Figure 1 shows some of the analyzed samples. 


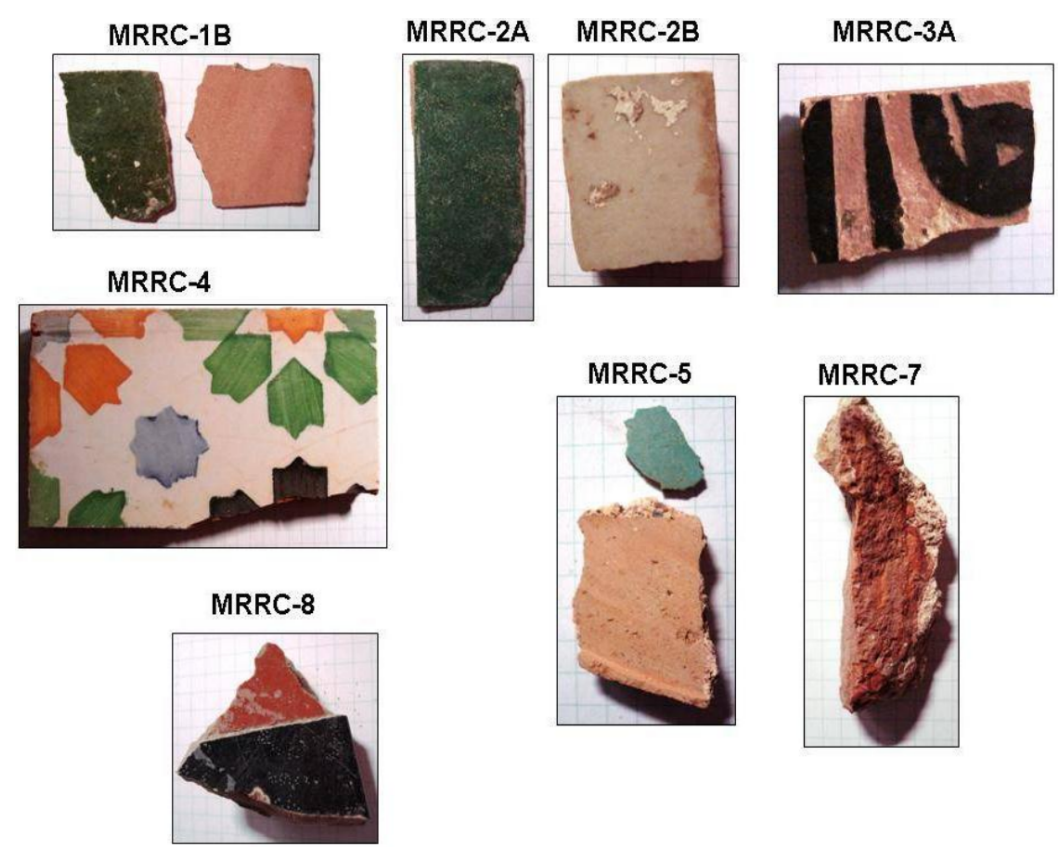

Figure 1. Some of the analyzed samples from Morocco. MRRC-1B: Abdelaziz; MRRC-2A and 2B, MRRC3A: Mosque; MRRC-4: Riad; MRRC-5: Bahia Palace; MRRC-8: Quartier.

\section{Experimental methodology}

In order to characterize this type of ceramics, X-ray-based techniques with a lateral resolution of the order of micrometer are required. In this regime, more detailed information about the different decorative motifs is supplied, with no interference between adjacent areas.

\subsection{Micro Energy Dispersive X-ray Fluorescence (EDXRF)}

For elemental determination, an Energy Dispersive X-ray Fluorescence (EDXRF) spectrometer, with micro beam capabilities was used. The $\mu$-EDXRF system consists on an X-ray tube OXFORD XTF5011 with a Mo anode and a Silicon Drift Detector (SDD) thermoelectrically cooled Vortex$60 \mathrm{EX}^{\circledR}$ from SII NanoTechnology U.S.A. Inc. (FWHM of $160 \mathrm{eV}$ at $\mathrm{Fe}-\mathrm{K} \alpha$ line energy) with an active area of $50 \mathrm{~mm}^{2}$ and a $12.5 \mu \mathrm{m}$ thickness Be window. The geometric arrangement of the instrumentation is on a $45^{\circ}$ detector to $\mathrm{X}$-ray tube geometry. The characteristic radiation and Bremsstrahlung were emitted by means of polycapillary focusing optics, allowing a focal spot of $100 \mu \mathrm{m}$ for Fe-K $\alpha$ [13]. The X-ray beam as well as the detector snout is housed in a vacuum chamber (figure 2), down to a $10 \mathrm{mbar}$ pressure. The system can also operate using a collimator, which allows an excitation area of about $1.2 \mathrm{~mm}^{2}$. The positioning of the sample was accomplished using two laser points and the analyzed spot could be visualized using a camera. The lasers are positioned in order to overlap at a distance of about $1.5 \mathrm{~mm}$ outside the chamber, which is the dimension of the focal of the polycapillary lenses. In this way we can assure that we are on focus to perform measurements. The operating conditions were $50 \mathrm{kV}$ and $1 \mathrm{~mA}$, in order to excite the Klines of such elements as $\mathrm{Sn}$ and $\mathrm{Sb}$. For this case, the collimator was used, since the transmission of the Polycapillary lens drops drastically for energies equal or greater than $30 \mathrm{keV}$. 


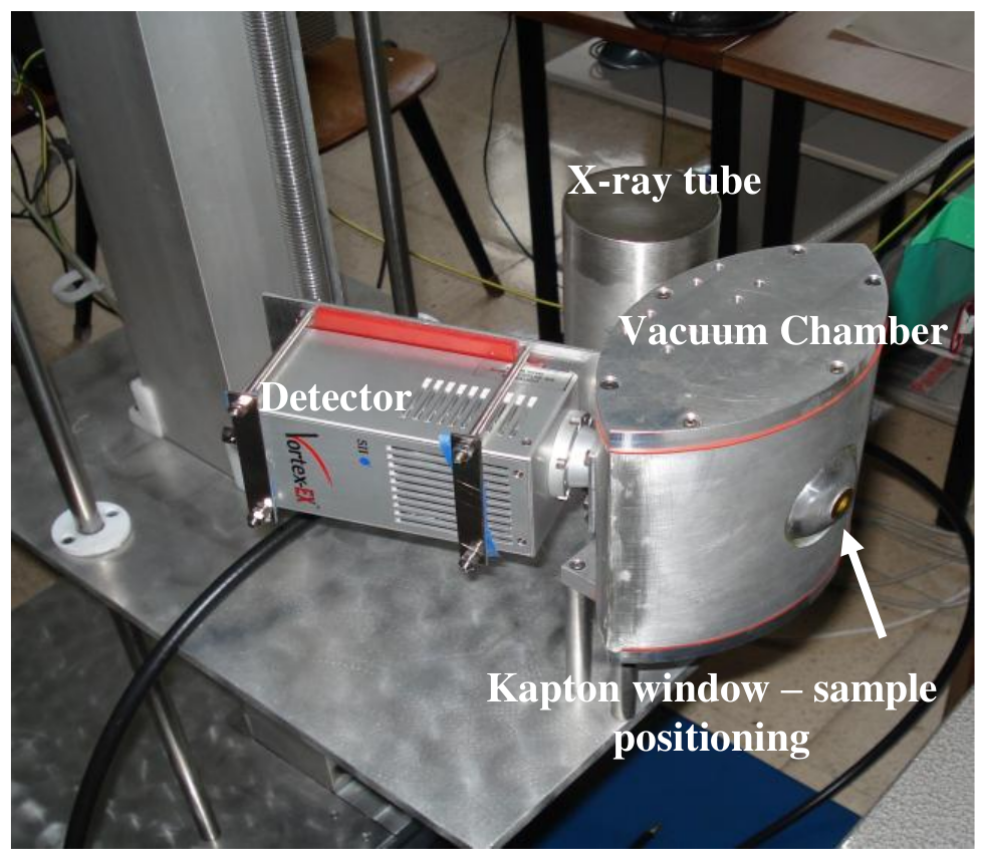

Figure 2. Outlook of the EDXRF spectrometer.

Each spectrum was collected during $300 \mathrm{~s}$ by a digital pulse processor with PI-SpecA software, using a multichannel (4096 channels) and recorded both in binary mode and in ASCII data mode in order to perform their evaluation using the PyMCA software code [14]. With this spectrometer, measurements were performed irradiating the sample surface perpendicularly, selecting in each sample each color.

\subsection{Wavelength Dispersive X-ray Fluorescence (WDXRF)}

Chemical quantities of the ceramic body were determined by Wavelength Dispersive X-ray Fluorescence (WDXRF) using a Philips PW 1840 spectrometer, with Cr anode tube. A sample prepared with 1:9 clay/flux (Spectromelt A12) ratio was fused to a glass bead. The $\mathrm{Na}_{2} \mathrm{O}$ and $\mathrm{K}_{2} \mathrm{O}$ contents were determined by flame photometry using a Corning 400 spectrometer. Loss on ignition was determined by heating the samples at $1000^{\circ} \mathrm{C}$ for 3 hours.

\section{Results and discussion}

\subsection{The ceramic body}

In the following, both qualitative and quantitative data for the ceramic body are presented. The measurements performed by EDXRF provide immediate qualitative and quantitative information about the raw materials used. The spectrum in figure 3 is an example of the elemental variability for the examined pieces. As expected, for a ceramic object, aluminum and silicon are the major elements, since they compose most of the mineral structures in clay and are highly abundant on Earth. So, it is appropriate focusing on rock-forming minerals as all clays derivate from rocks. 


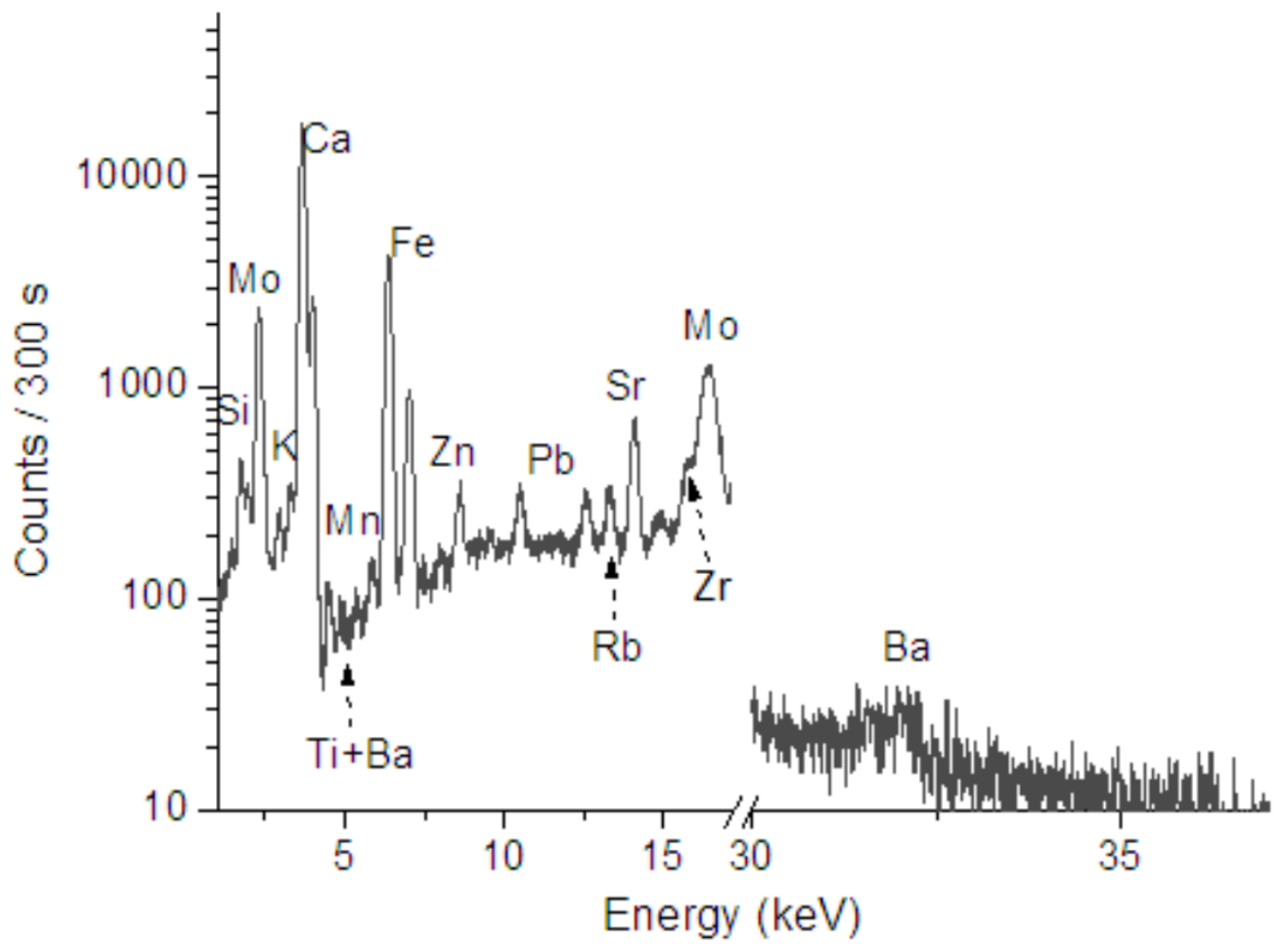

Figure 3. EDXRF spectrum obtained for the ceramic body for sample MRRC-4.

Despite the fact that clays used by potters are sediments they come from igneous rocks and it is useful to understand their crystallization process and the formation of the igneous materials [1].

Several samples from the same monument were analyzed and the concentrations of the major and minor compounds obtained by WDXRF are given. In order to evaluate immediately the differences and similarities between the different groups (monuments), the average concentrations for each one are plotted in figure 4 , for the elements which reveal more variability. The choice for these elements was made based on the available literature on this subject [10]. The major and minor compounds were plotted separately due to the difference in the order of magnitude.

First of all Silicon ( $\mathrm{Si}$ ) is not plotted in figure 4, as it is the major compound used for the ceramic body formation. Its concentration ranges between $53.5-56.2 \%$ and provide, therefore, no contrast between the different groups of samples. Aside of $\mathrm{Si}$, oxides of $\mathrm{Al}, \mathrm{Ca}$ and $\mathrm{Mg}$ are within the major components of clays. One sees that the concentration values for $\mathrm{Al}$ are not very high (12.3-18.6\%), however the range is quite broad. From figure 4 one concludes that the samples from Riad and Mosque Massine assume the higher values of Al. From this plot we can assess that the concentration of $\mathrm{K}, \mathrm{Ti}$ and $\mathrm{Mn}$ is quite uniform among all samples groups and considering the alkali components ( $\mathrm{Na}$ and $\mathrm{K}$ ), the values for $\mathrm{K}(1.9-3.5 \%)$ are higher than the ones for $\mathrm{Na}(0.3-$ $0.7 \%$ ). Ca shows some considerable variability between the groups, between 8.9-16.5\%, which is inversely proportional to the variability of $\mathrm{K}$. Complementing this information with the one obtained from the Scatter Matrix Plot (figure 5), it is noticeable that $\mathrm{Ca}$ and $\mathrm{K}$ have this inverse relationship. Still focusing on the Scatter Matrix, one realizes for example that $\mathrm{Fe}$ and $\mathrm{Ca}$ are 

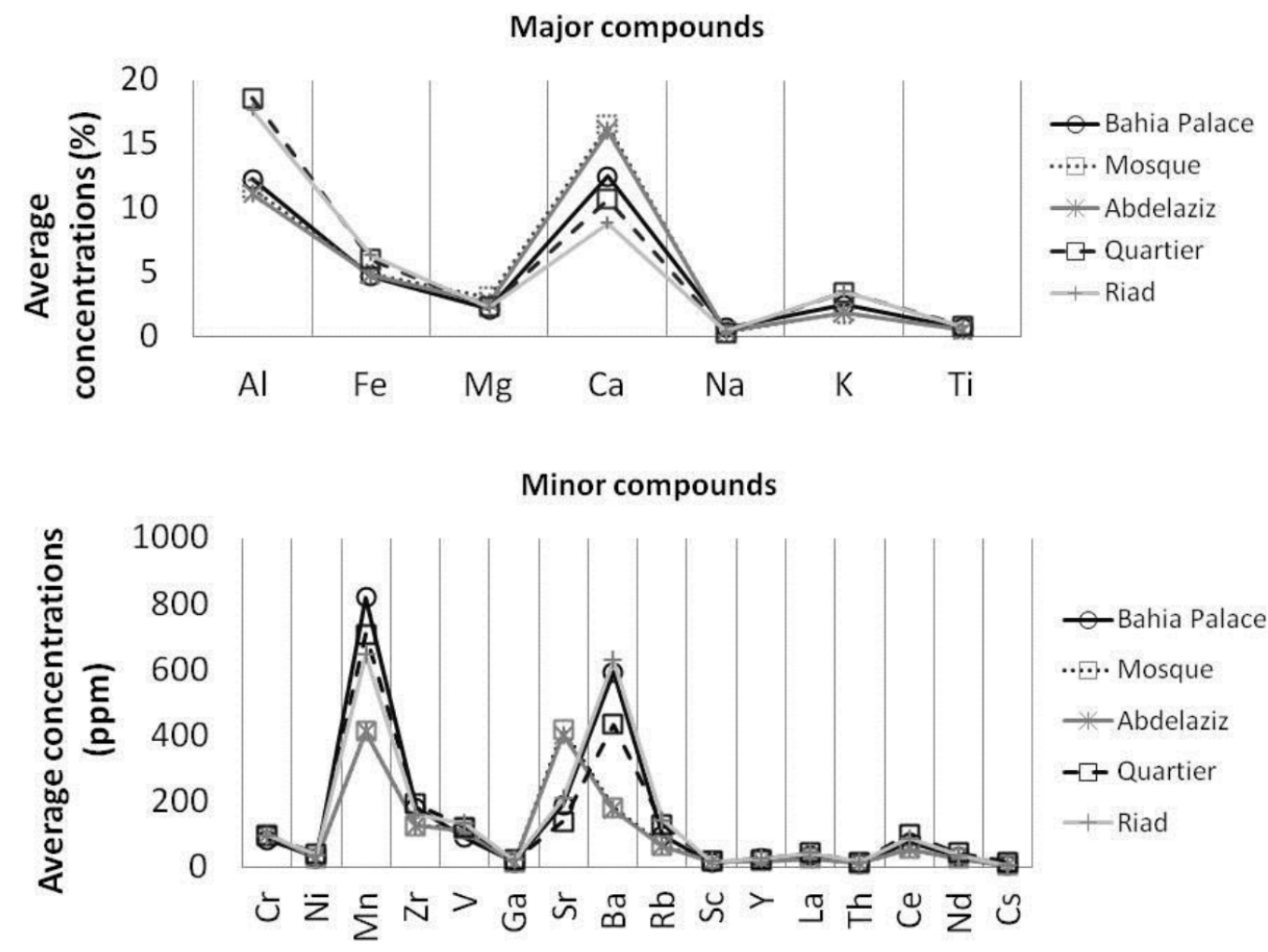

Figure 4. Average concentrations for the elements which have higher variability in the ceramic body obtained by WDXRF. The upper plot corresponds to the major elements (in \%) and the lower one to the minor elements (in $\mu \mathrm{g} \cdot \mathrm{g}^{-1} \equiv \mathrm{ppm}$ ). The total concentration obtained for the minor elements is less than $1 \%$.

inversely proportional as well, but between Fe and $\mathrm{K}$ there is a positive relationship for all groups of samples.

Regarding the minor compounds by inspection of figure 4 (lower graphic), the elements showing a higher variability between groups are $\mathrm{Mn}\left(413-820 \mu \mathrm{g} \cdot \mathrm{g}^{-1}\right), \mathrm{Ba}\left(180-630 \mu \mathrm{g} \cdot \mathrm{g}^{-1}\right), \mathrm{Sr}$ $\left(138-420 \mu \mathrm{g} \cdot \mathrm{g}^{-1}\right)$ and to a lower extend $\mathrm{Zr}\left(127-193 \mu \mathrm{g} \cdot \mathrm{g}^{-1}\right)$ and $\mathrm{Ce}\left(57-100 \mu \mathrm{g} \cdot \mathrm{g}^{-1}\right)$. Interesting to observe is the behavior between $\mathrm{Sr}$ and $\mathrm{Ba}$ for the samples from Saint Sidi Abdelaziz and Mosque Massine. Sr and Ba are inversely correlated. In fact, regarding the literature on this matter [1], we learn that the $\mathrm{Sr} / \mathrm{Ba}$ ratio varies during the process of crystallization of igneous rocks and both often replace $\mathrm{K}$.

\subsection{The colors}

To enhance the capabilities of working with micrometer-resolved techniques, on figure 5 and figure 6, an overlap of spectra obtained from different motifs on a surface of a sample is shown. Analyses on such detailed decorative motifs are possible with a microbeam only.

\subsection{The white/glaze}

Figure 7a shows an overlap of spectra which correspond to the white surfaces of samples from different monuments (groups). All show similar elemental distribution but the samples from the 


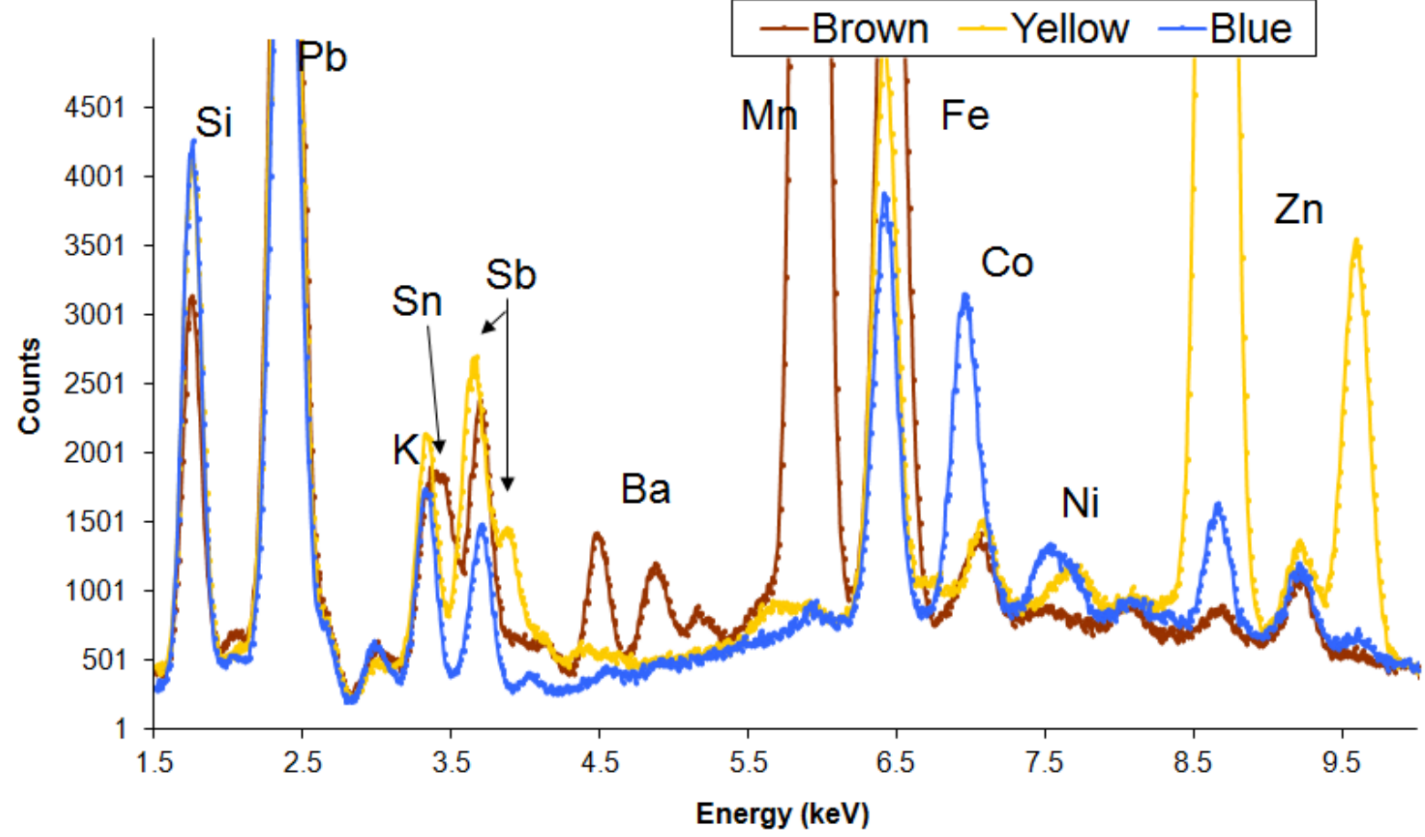

Figure 5. Spectra obtained from different colored motifs by $\mu$-EDXRF. Faience sample from Coimbra (Portugal) belonging to the XVII century.

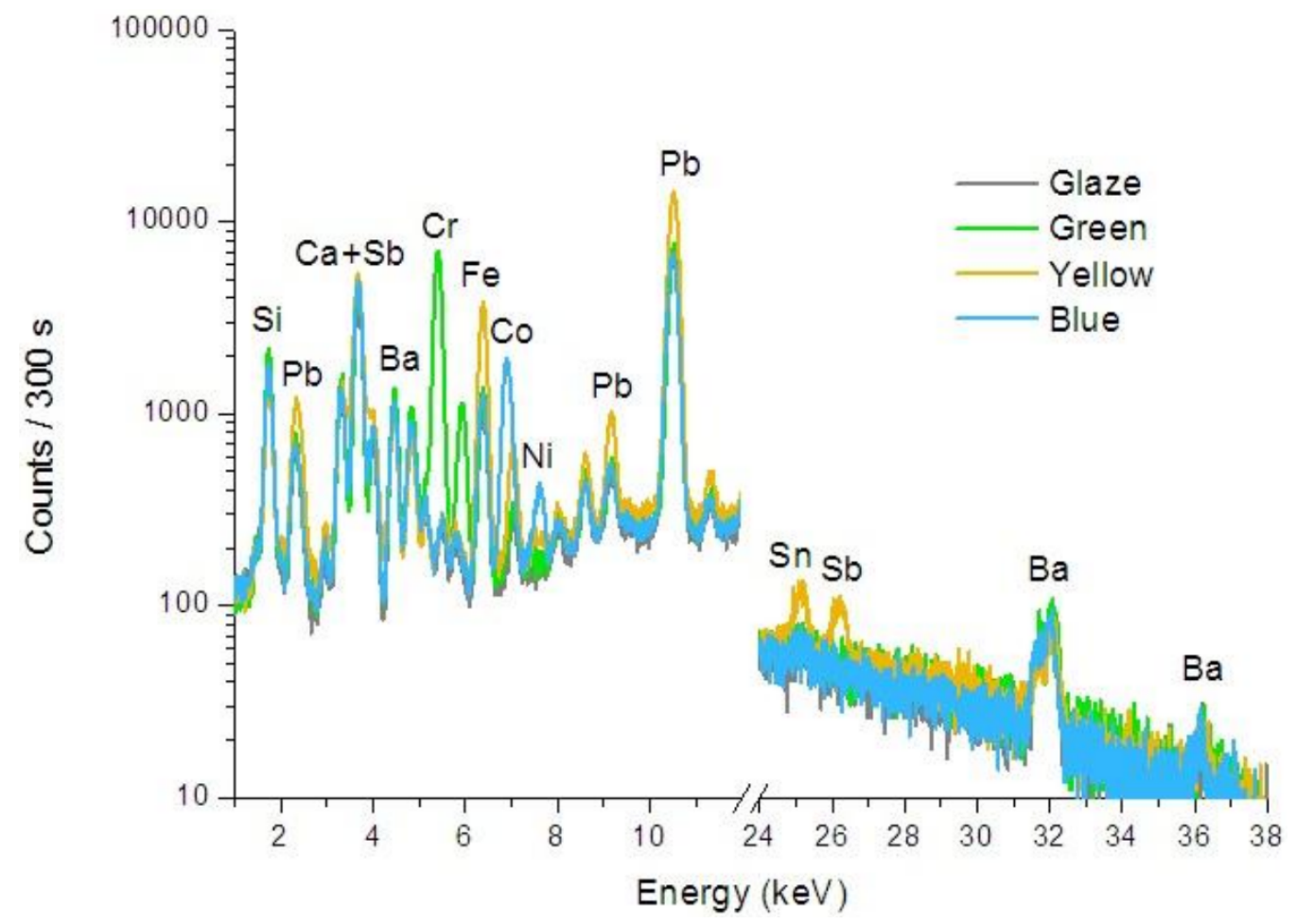

Figure 6. Spectra obtained from different colored motifs by EDXRF. Sample from Morocco, MRRC-4. 


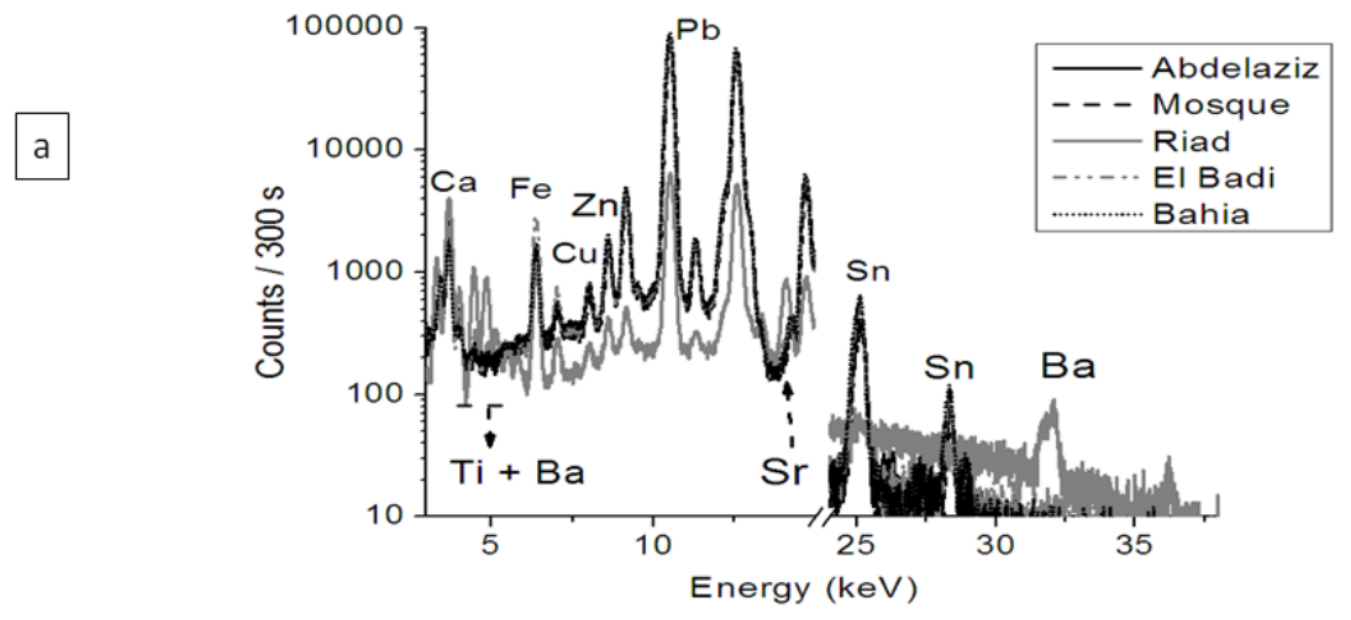

$\mathrm{b}$

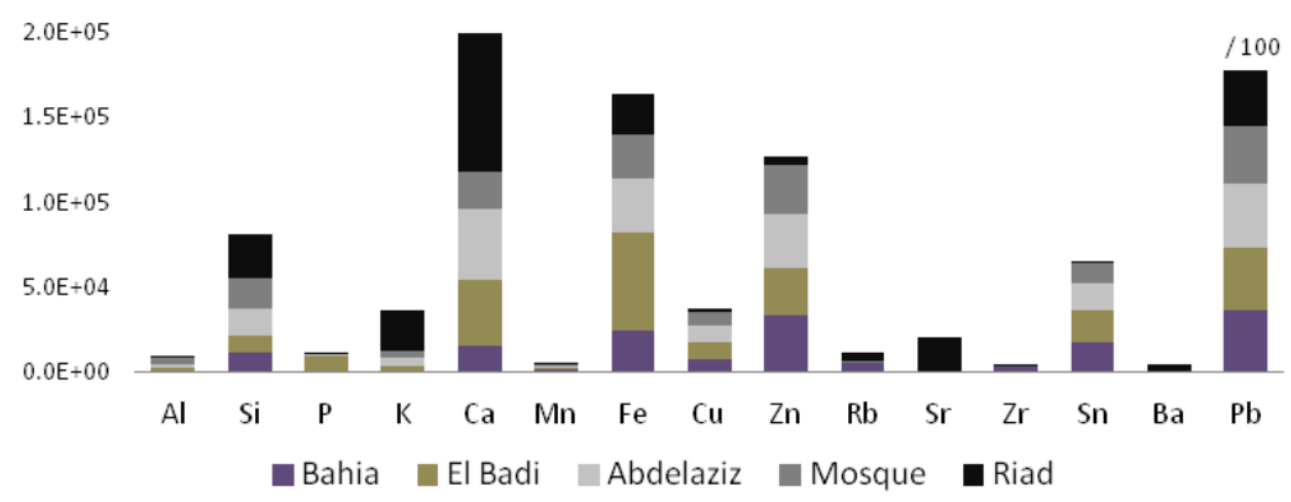

Figure 7. a) EDXRF spectra of the white surface areas on samples from different monuments; b) net intensity relationships between the 5 monuments ( $\mathrm{Pb}$ values must be multiplied by 100).

Ancient Riad show peaks of $\mathrm{Sr}$ and $\mathrm{Ba}$ together with a lower intensity of $\mathrm{Pb}$ (as it is shown in figure $7 b$ ). In all cases one see that the raw materials used are quite similar to the ones used to form a glaze, as in Azulejos (Portuguese wall tile samples). A comparison between these two types is given in figure 8. From this figure we see that the white color of the sample from the Mosque has a mixture quite similar to the glaze of the sample from Lisbon, which reveals a higher count rate for $\mathrm{Mn}$ and Sn when compared to the sample from the Mosque. However, the sample from the Riad reveals much less $\mathrm{Pb}$ than both others (one order of magnitude less) together with the presence of $\mathrm{Sr}$ and $\mathrm{Ba}$.

\section{Conclusions}

XRF has proven to be a powerful and reliable technique able to provide immediate answers related to Cultural Heritage objects. Having the possibility to perform micrometer-resolved measurements (via a Polycapillary lens, in our case) has revealed to be of great importance in order to distinguish detailed decoration motifs, without having interference from neighbouring zones. 


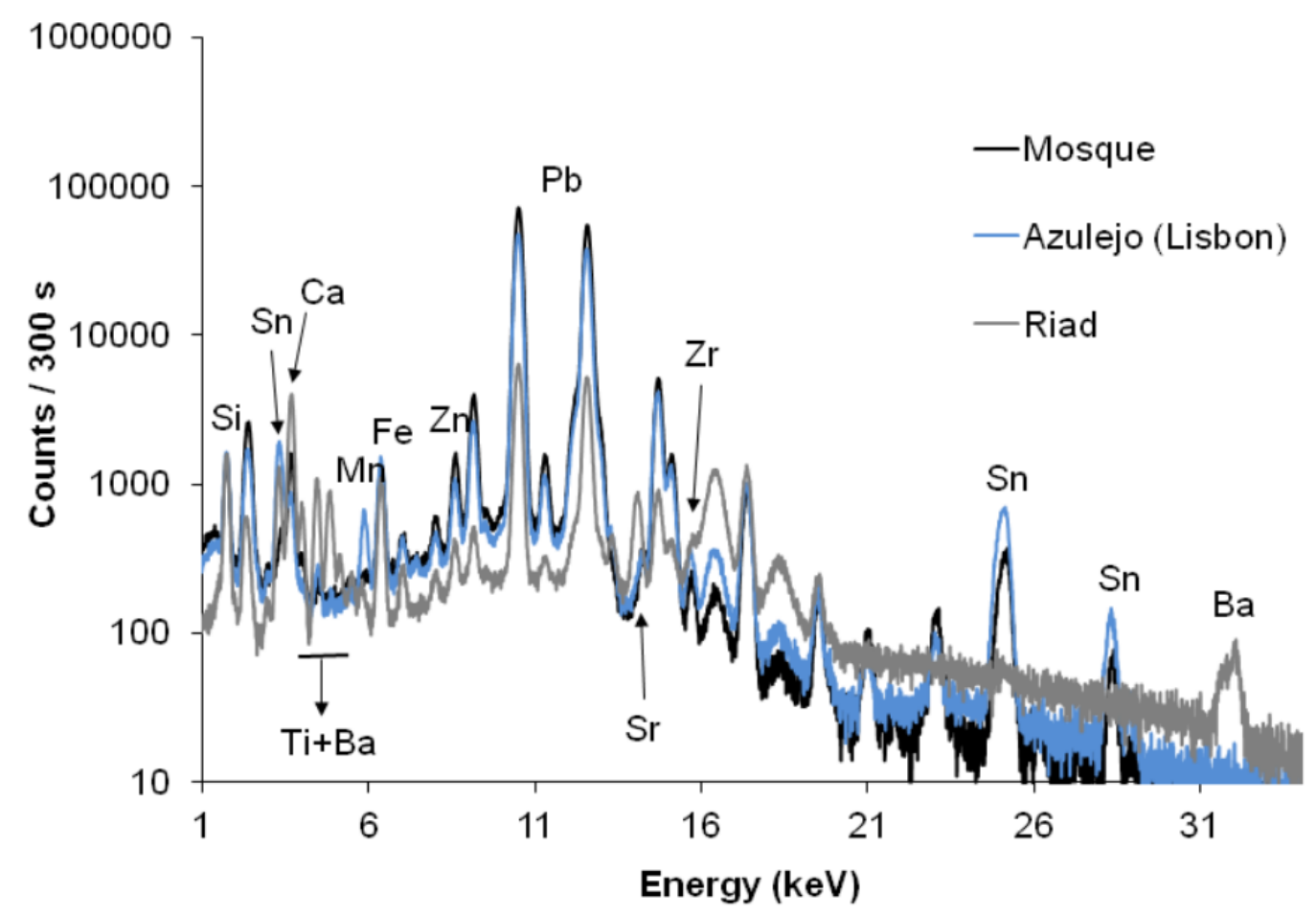

Figure 8. EDXRF spectra comparison between white surface areas on two samples from Morocco (Mosque and Riad) and a glaze from an Azulejo from Lisbon.

In our case in particular, and due to these technical capabilities, differences between the glaze and pigments composition were identified. In conclusion, this study brings novelty to the universe of pottery, as it is the first time that a compositional investigation is performed in such typical Moroccan artworks (Zellij) and its composition is associated to Portuguese tiles. Differences in the composition of the ceramic body were found as well as in the colored layers. Especially the samples from the Riad reveal different mixture components, such as $\mathrm{Ba}$, and a much lower content in $\mathrm{Pb}$, when compared to the other samples.

\section{References}

[1] P.M. Rice, Pottery analysis: a sourcebook, The University of Chicago Press, Chicago U.S.A. (1987).

[2] A. Zarghili, J. Kharroubi and R. Benslimane, Arabo-Moresque decor images retrieval system based on spatial relationships indexing, J. Cult. Herit. 9 (2008) 317.

[3] L. Casas, J.L. Briansó, A. Álvarez, K. Benzzi and J. Shaw, Archaeomagnetic intensity data from the Saadien tombs (Marrakech, Morocco), late 16th century, Phys. Chem. Earth 33 (2008) 474.

[4] http://www.zellige.ma/zellij-moroccan.html, retrieved 25 Sep 2012.

[5] S.S. Blair and J.M. Bloom, The art and architecture of Islam 1250-1800, Yale University Press, New Haven U.S.A. (1995), pg. 123.

[6] G. Deverdun, Marrakech, des origines à 1912, Editions Frontispice, Casablanca Morocco (2004), pp. 542-546. 
[7] R. Hillenbrand, Islamic architecture, Edinburgh University Press, Edinburgh U.K. (1999), pp. 271-272.

[8] E.J. Grube, Architecture of the Islamic world: its history and social meaning, G. Michell ed., Thames and Hudson, London U.K. (1996), pg. 218.

[9] M. Métalsi, C. Tréal and J.-M. Ruiz, The imperial cities of Morocco, Terrail, Paris France (2000), pp. 107-111.

[10] H.W. Catling, E.E. Richards and A.E. Blin-Stoyle, Composition and provenance of Mycenaean and Minoan pottery, The Annual of the British School at Athens 58 (1963) 94.

[11] J. Meunié, Le grand Riad et les bâtiments saâdiens du Badi à Marrakech selon le plan publié par Windus, Hespéris 44 (1957) 129.

[12] http://www.couleurs-maroc.com/numero10/histoire-secrete-marrakech.htm.

[13] A. Guilherme, S. Pessanha, M.L. Carvalho, J.M.F. dos Santos and J. Coroado, Micro energy dispersive X-ray fluorescence analysis of polychrome lead-glazed Portuguese faiences, Spectrochim. Acta B 65 (2010) 328.

[14] V.A. Solé, E. Papillon, M. Cotte, Ph. Walter and J. Susini, A multiplatform code for the analysis of energy-dispersive X-ray fluorescence spectra, Spectrochim. Acta B 62 (2007) 63. 